\title{
Learning of predatory skills by shorecrabs Carcinus maenas feeding on mussels and dogwhelks
}

\author{
P. N. Cunningham and R. N. Hughes \\ School of Animal Biology, University College of North Wales, Bangor, Gwynedd LL57 2UW, Wales, United Kingdom
}

\begin{abstract}
Carcinus maenas (L.) used 5 recognizable methods to attack mussels and 3 methods to attack dogwhelks. The frequency of usage varied among methods but did not change as crabs gained experience of the prey. The mean number of attacks required to open prey decreased with practice, irrespective of the methods used. The mean time to break open a prey decreased by a factor of about 0.30 for mussels and about 0.28 for dogwhelks after 5 to 6 prey had been eaten. Reductions in breaking time were both less marked and slower when mussels and dogwhelks were presented alternately to the crabs. Mean breaking times for the first prey offered in trials separated by over $4 \mathrm{~d}$ were similar to those associated with naive crabs, but were shorter in trials separated by smaller time intervals. Skills were therefore gained within 1 to $2 \mathrm{~h}$ but were lost at a much slower rate. Crabs have a learning capacity that can cause prey items to become transposed in rank and which could lead to switching under appropriate circumstances. Alternate handling of dissimilar prey reduces learning efficiency and could increase the disparity in abundances of alternative prey necessary for switching to occur.
\end{abstract}

\section{INTRODUCTION}

The modification of attack efficiencies resulting from experience with specific prey has become an important concept in theoretical treatments of density-dependent predation. Development of 'searching images' (Tinbergen, 1960) may accentuate density-dependent predation on alternative kinds of prey, perhaps causing 'switching' in the short term (Murdoch, 1969; Murdoch and Oaten, 1975) or 'apostatic selection' in the long term (Clark, 1969). Improvement of attack efficiencies gained through practice on abundant prey might reduce handling times and so increase the profitabilities of these prey to the predator. Thus it is theoretically possible for the profitabilities of alternative prey to become transposed as their relative abundance changes, perhaps causing a switch of diet (Hughes, 1979).

There are few published data, however, on the degree to which attack efficiencies change as predators gain experience with specific prey. Notonecta glauca (L.) increased its attack success rate on Asellus aquaticus L. as experience was gained, but did not develop searching images (Lawton et al., 1974). Akre and Johnson (1979) observed Anomalagrion hastatum
(Say) to switch between diets of Daphnia magna Strauss and Simocephalus vetulus Schodler, suggesting, but not proving, that the switch involved the substitution of alternative ambush and stalking searching modes. Both mean intercatch interval and handling time decreased during catch sequences when Notonecta glauca and $N$. maculata (Fabricius) fed on larvae of Aedes aegypti (L.), but it was not possible to tell whether these trends were caused by the development of searching images or by filling of the gut (Giller, 1980). For physiological reasons, handling time decreased when Aphelinus thomsoni Graham foraged among Drepanosiphum platanoidis (Schrank) which served both as food and hosts for oviposition (Collins et al., 1982).

Here, we present data showing that previously naive Carcinus maenas (L.) quickly become more efficient at attacking Mytilus edulis (L.) and Nucella lapillus (L.) as they gain experience of these prey separately, but that a mixed diet partially impedes the learning process. Numerical models, describing both the rate of learning and the rate at which learnt skills are lost by the shorecrab, are used to demonstrate how learning may cause the profitabilities of mussels and dogwhelks to become transposed in rank. 


\section{METHODS}

Carcinus maenas of 5.5 to $7.0 \mathrm{~cm}$ carapace width were caught by drop net from Menai Bridge pier, Anglesey. Nucella lapillus were collected from Penmon, Anglesey and Mytilus edulis from Heysham, Morecambe Bay, Lancashire. Only male crabs were used for experimentation, thus avoiding possible sexual differences in predatory behaviour. For 1 mo prior to experimentation, crabs were fed on flesh dissected from the mussels and dogwhelks. Crabs that would not feed readily on both foods were discarded. During experiments, crabs were kept separately in $23 \times 43 \mathrm{~cm}$ Perspex aquaria connected in series in a closed circuit flowing seawater system at ambient room temperatures of about $15^{\circ} \mathrm{C}$.

The experiments were designed to quantify any changes in the speed and success with which the crabs attacked entire mussels or dogwhelks as they gained experience of these prey and to determine whether a mixed diet would interfere with learning. Methods used by the crabs to open mussels and dogwhelks were categorized and their frequency and success recorded throughout the experiments. Breaking time, the time elapsing between initial contact with a prey and the first bite of flesh, was measured for each prey eaten. The time taken to eat the flesh was not recorded, since it could be strongly affected by changing hunger levels during the experiments.

Feeding trials were initiated by placing a mussel or dogwhelk in each tank. Prey were replaced as soon as the crabs resumed foraging after consuming a prey. Replacement of prey continued until breaking time stopped decreasing. This usually occurred when up to 6 prey had been eaten, so that feeding trials lasted 1 to $2 \mathrm{~h}$. Three sets of feeding trials were run. In the first set, designed to measure the speed and extent of learning, 12 crabs were fed mussels and $11 \mathrm{crabs}$ were fed dogwhelks in continuous sequences. In the second set, designed to measure the effect of a mixed diet on learning, 11 crabs were fed sequences of alternating mussels and dogwhelks, commencing with a mussel, and 11 crabs were fed mussels of two alternating sizes, starting with a smaller mussel. In the third set, designed to measure the rate of decay of learned skills, 5 crabs were fed up to 7 mussels in 1 to $2 \mathrm{~h}$ trials at intervals of $0,24,48,100$ and $200 \mathrm{~h}$, and 7 crabs were fed mussels in trials at intervals in the reverse order. Eight crabs were fed dogwhelks in trials at similar increasing intervals up to $300 \mathrm{~h}$ and 3 crabs were fed dogwhelks at decreasing intervals. When trials were separated by more than $48 \mathrm{~h}$, flesh of the appropriate prey was fed to the crabs to keep hunger levels as constant as possible. Fewer crabs were used in some trials than in others because moulting caused individu- als to cease feeding. Crabs fed mussels or a mixed diet were not subsequently used in trials with dogwhelks, and vice versa. Mussels of 1.0 to $2.8 \mathrm{~cm}$ shell length and dogwhelks of 0.9 to $1.9 \mathrm{~cm}$ shell height were used in most trials, the precise sizes $( \pm 0.1 \mathrm{~cm})$ being matched to the sizes of the crabs and chosen to be the most profitable as judged from data in Elner and Hughes (1978) and Hughes and Elner (1979). In trials with 2 size classes of mussels, prey of 3.0 to $3.5 \mathrm{~cm}$ shell length were used in addition to the 1.0 to $2.8 \mathrm{~cm}$ 'optimal' mussels.

\section{RESULTS}

Crabs used 5 recognizable methods to open mussels: (a) crushing across the umbonal end, umbone held uppermost, used in $46 \%$ of attacks; (b) crushing across the umbonal end, umbone held downmost, used in $10 \%$ of attacks; (c) crushing across the posterior end, umbone held uppermost, used in $3 \%$ of attacks; (d) crushing across the posterior end, umbone held downmost, used in $21 \%$ of attacks; (e) prising the shell apart, used in $20 \%$ of attacks.

Crabs used 3 recognizable methods to open dogwhelks: (f) crushing across the columellar end along any radius, used in $60 \%$ of attacks; $(\mathrm{g})$ crushing across the apical end, usually across the last whorl, used in $35 \%$ of attacks; (h) attacks around the lip of the shell or along the columellar axis, used in $5 \%$ of attacks. The frequencies with which the methods of attack were used did not change significantly during trials $(\mathrm{F}=0.02$, d.f. $=6,42, \mathrm{P}>0.05)$.

For mussels, the mean success rate of Method a remained at about $10 \%$ throughout trials, the mean success rate of Method $b$ varied erratically between 0 and $35 \%$, Method c always failed, Method d succeeded only in initial encounters, giving an overall success rate of $3 \%$, Method e was always successful. For dogwhelks, the mean success rate of Method $f$ increased from about 20 to $30 \%$ during trials. The mean success rate of Method $g$ increased from about 5 to $25 \%$ when up to 4 dogwhelks had been eaten and fluctuated erratically thereafter. Method h was never successful.

The mean times to break open prey in the first set of trials decreased asymptotically to about $30 \%$ of the initial value after 5 to 6 mussels, or after 5 to 6 dogwhelks, had been eaten (Fig. 1). The mean number of attacks required to break open a prey, irrespective of method, decreased linearly from 4.7 to 1.6 when 5 to 6 mussels had been eaten and decreased asymptotically from 6.6 to 1.2 when 5 to 6 dogwhelks had been eaten (Fig. 2).

The mean time to break open the first mussel offered in the second set of trials was not significantly different 


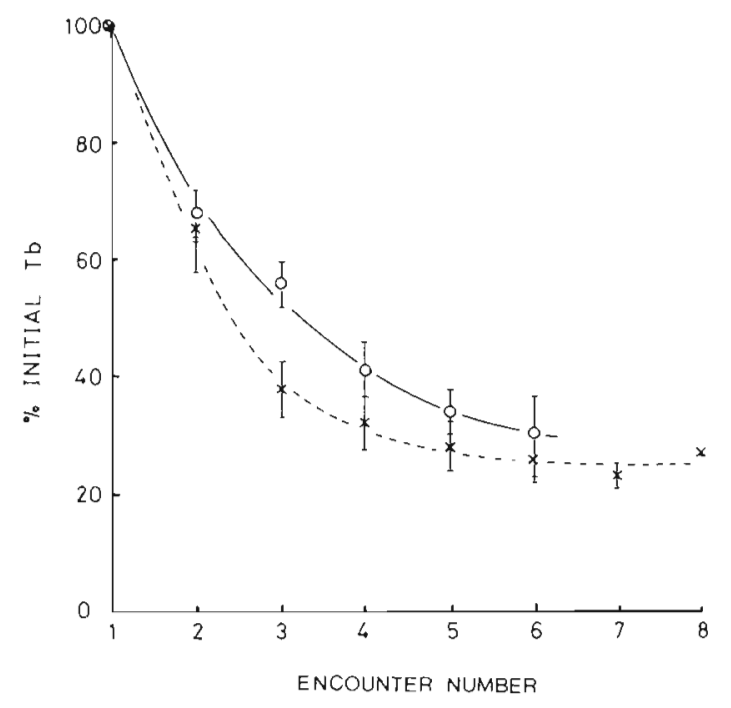

Fig. 1. Carcinus maenas. Mean breaking times, with standard errors, for successive prey eaten, expressed as percentages of the time taken to break open the first prey encountered, in

trials with monospecific diets. O mussels, $\times$ dogwhelks

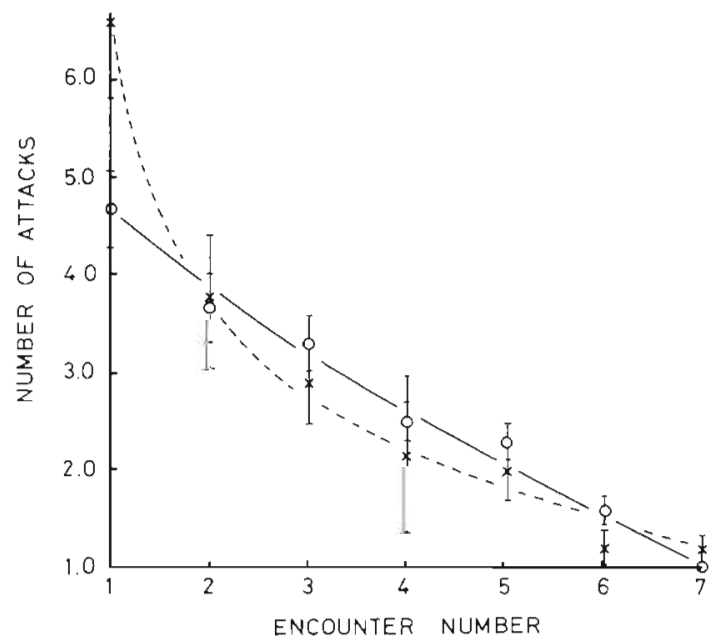

Fig. 2. Carcinus maenas. Mean number of attacks required, with standard errors, to break open prey eaten successively. Symbols as for Fig. 1

from that in the first set of trials $(t=0.19$, d.f. $=22$, $P>0.05)$. The mean time to break open mussels offered alternately with dogwhelks decreased to about $30 \%$ of the initial value (Fig. 3), but did so less quickly than when crabs were fed on mussels alone (Fig. 1). The mean time to break open dogwhelks presented alternately with mussels decreased to about $50 \%$ of the initial value, a significantly smaller decrease than in the diet of dogwhelks alone (using mean handling times for sixth prey eaten, $t=8.25$, d.f. $=10$, $\mathrm{P}<0.001$ ).

The mean time to break open 1.0 to $2.8 \mathrm{~cm}$ mussels offered alternately with larger mussels decreased to about $30 \%$ of the initial value, as when the smaller

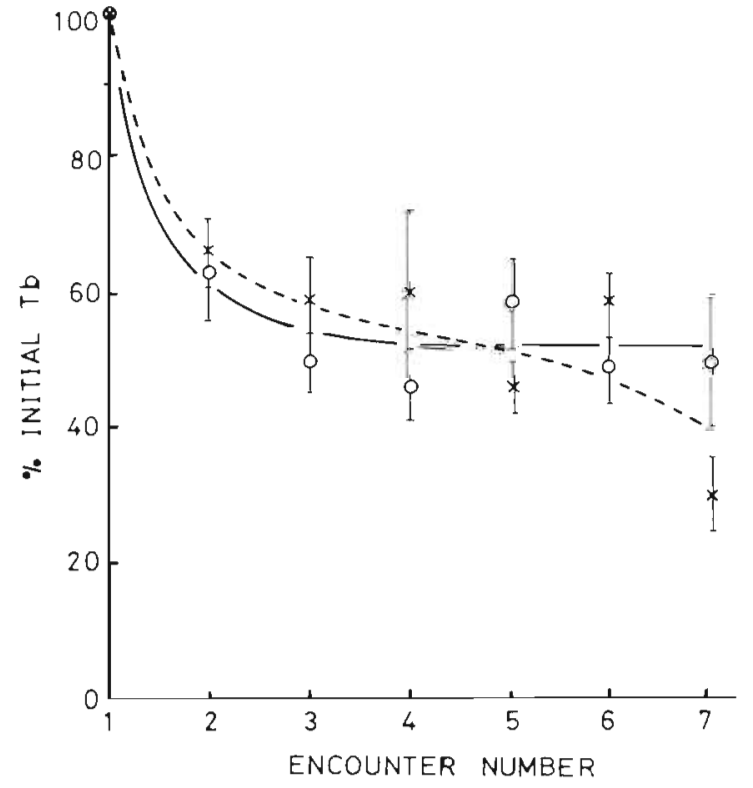

Fig. 3. Carcinus maenas. Mean breaking times, with standard errors, for successive prey eaten, expressed as percentages of the time taken to break open the first prey encountered, in trials with mixed diets. Symbols as for Fig. 1

mussels alone were offered in the first set of trials. Acquisition of opening skills was therefore independent of mussel size over the range used.

The mean times to break open the last prey in the trials separated by increasing or decreasing time intervals were not significantly different among trials (mussels, time intervals increasing, $F=1.28$, d.f. $=4,20$, $\mathrm{P}>0.03$, time intervals decreasing, $\mathrm{F}=0.26$, d.f. $=$ $6,28, \mathrm{P}>0.8$; dogwhelks, time intervals increasing, $\mathrm{F}=$ 1.37, d.f. $=7,32, \mathrm{P}>0.2$, time intervals decreasing, $\mathrm{F}=$ 0.78 , d.f. $=2,12, \mathrm{P}>0.55$ ). The mean time to break open the first prey offered tended to be less in trials separated by shorter time intervals (Fig. 4), the difference being

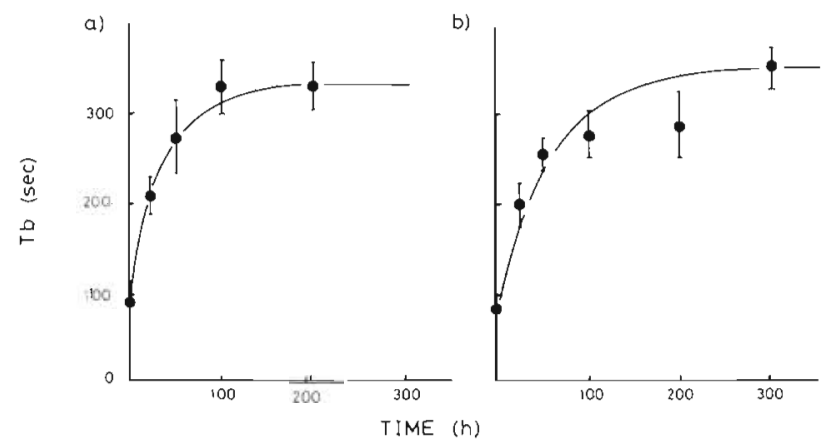

Fig. 4. Carcinus maenas. (a) Mean breaking time for the first mussel eaten in a new trial (foraging bout) plotted as a function of the time elapsing since the last mussel eaten in the previous trial. Data are means with standard errors pooled from experiments with increasing and decreasing time intervals between trials (see text). Curve fitted by eye and used to derive Equation (2) (see 'Discussion'). (b) As (a), but for dogwhelks 
more pronounced among decreasing time intervals (mussels, time intervals increasing, $\mathrm{F}=3.98$, d.f. $=$ $4,20, P<0.05$, time intervals decreasing, $F=9.04$, d.f. $=6,28, \mathrm{P}<0.001$; dogwhelks, time intervals increasing, $F=0.70$, d.f. $=7.32, \mathrm{P}>0.5$, time intervals decreasing, $F=7.38$, d.f. $=2,12, P<0.01$ ).

\section{DISCUSSION}

The methods used by Carcinus maenas to open Mytilus edulis in the present experiments were similar to those described by Elner (1978). Crabs held mussels vertically, using the smaller chela, and attempted to crush the opposite end with the larger chela. Probably because of a greater mechanical advantage, attempts to crush the umbonal region were more successful than attempts to crush the much wider posterior region. The prising method tended to be used when other methods had already partially broken the shell and, by persisting, crabs could always force open mussels.

The methods used by crabs to open dogwhelks were similar to those described by Hughes and Elner (1979) and appeared to be determined by the grip offered by the geometry of the shell. Again probably because of a greater mechanical advantage, attempts to crush the apical region of the shell were more successful than attempts to crush other regions.

Although success rate differed among the methods of attack, the frequencies with which these methods were used did not change significantly during trials. Therefore, the marked reduction in the number of attempts to break open individual prey as crabs became more experienced with mussels or dogwhelks (Fig. 2) must have been due to an increased effectiveness of the methods of attack. The success rates of individual methods of attacking mussels were too variable for improvement among them to be detected, but crabs clearly improved their ability to crush dogwhelks in the apical and columellar regions.

The acquisition of predatory skills, however, showed up more strongly in the way mean handling times decreased as a result of experience. Not only was there a reduction of handling times by a factor of about 0.3 , but this improvement was achieved after crabs had experienced only 5 to 6 prey. Crabs appeared to have lost the acquired skills in about $4 \mathrm{~d}$, but partial retention of skills persisted for at least $2 \mathrm{~d}$. These observations could be explained if the skillfulness of a crab at any time represented the balance between a high rate of learning and a much lower rate of forgetting.

Hughes (1979) developed a model of diet selection, based on the energy maximisation premise (Charnov, 1976), but incorporating a submodel in which prey handling time was made a function of the rate at which the predator encounters its prey. In the submodel, handling time at a given instant represented the resultant effect of learning from previous encounters and forgetting since the last encounter. Two predictions arising from the submodel were that the profitabilities of prey could become transposed in rank as their rates of discovery by the predator changed and that, with appropriate profitabilities and densities of prey, an optimally foraging predator should switch its specialized diet from one prey to the other.

The present data were incorporated in a modified version of Hughes' (1979) model to investigate the possibility of the profitabilities of mussels and dogwhelks being transposed in rank, thus providing the opportunity for switching. Data on breaking time as a function of the number of consecutive prey eaten during a foraging bout, in which only one species was eaten, were fitted by eye (Fig. 5), yielding the equation:

$\mathrm{Tb}=\mathrm{Tmin}+(\mathrm{Tmax}-\mathrm{Tmin}) \mathrm{e}^{-\mathrm{kN}}$

where $\mathrm{Tb}=$ breaking time; $\mathrm{Tmin}=$ minimum value of breaking time attainable by learning ( $90 \mathrm{~s}$ for mussels,

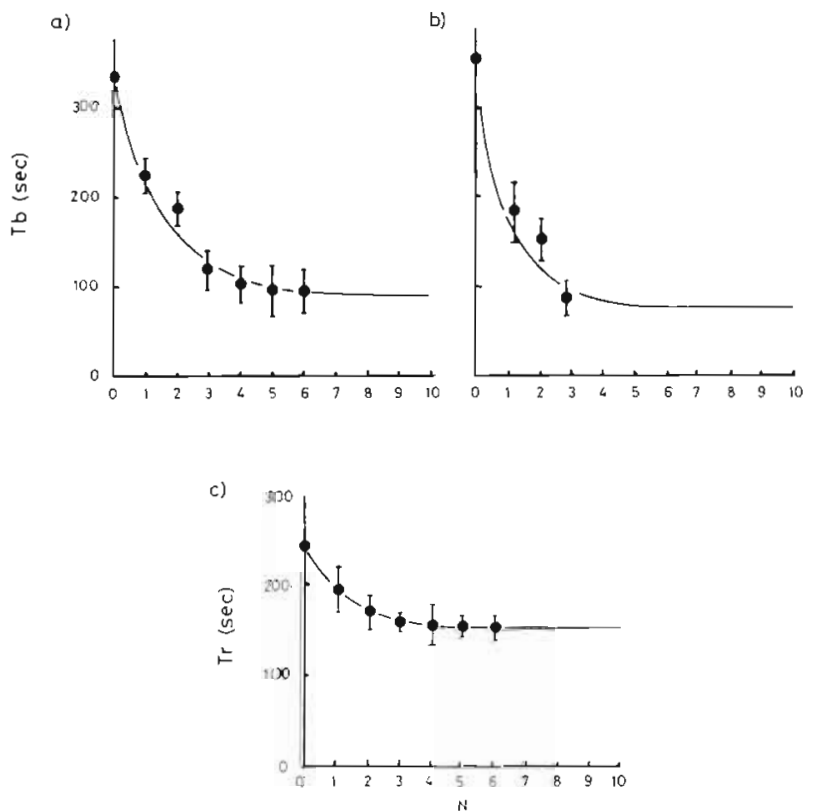

Fig. 5. Carcinus maenas. (a) Mean breaking times for consecutive mussels eaten during a foraging bout. Curve fitted by eye and used to derive Equation (1) (see 'Discussion'). (b) As (a), but for dogwhelks. (c) Mean removal times for consecutive mussels extracted from a clump during a foraging bout. Data are means with standard errors from Cunningham (1983). Curve fitted by eye

$84 \mathrm{~s}$ for dogwhelks); $\mathrm{Tmax}=$ maximum value of breaking time unmodified by learning (330 s for mussels, $352 \mathrm{~s}$ for dogwhelks); $\mathrm{k}=$ instantaneous rate of shortening of $\mathrm{Tb}$ (prey eaten) $)^{-1}$ (0.631 for mussels, 
0.980 for dogwhelks); $\mathrm{N}=$ number of consecutive prey eaten in the foraging bout.

In nature, shorecrabs will encounter mussels tightly packed in clumps and it has been shown (Cunningham, 1983) that a significant removal time, Tr, is required for extracting a mussel from a clump. Tr was related to the number of consecutive mussels eaten in the foraging bout (Fig. 5) by an equation (1a) similar to that for $\mathrm{Tb}$, in which $\operatorname{Trmin}=157 \mathrm{~s}$; $\operatorname{Trmax}=244 \mathrm{~s}$; $\mathrm{k}=0.837$.

The equations for $\mathrm{Tb}$ and $\mathrm{Tr}$ assume that there is no lengthening of these variables, due to forgetting, between successively eaten prey during a foraging bout. The effects of forgetting on $\mathrm{Tb}$ for mussels and dogwhelks were predicted from the following equation, fitted by eye to data on breaking time as a function of the time elapsing between consecutive foraging bouts (Fig. 4):

$\mathrm{Tb}=$ Tbmax $\left[1-((\mathrm{Tbmax}-\mathrm{Tbmin}) / \mathrm{Tb} \max ) \mathrm{e}^{-\mathrm{kT}}\right]$

where $\mathrm{T}=$ time elapsing between consecutive foraging bouts; $\mathrm{k}=$ instantaneous rate of increase of $\mathrm{Tb}$ $\left(0.029 \mathrm{~h}^{-1}\right.$ for mussels; $0.016 \mathrm{~h}^{-1}$ for dogwhelks). Data were not available for estimating the effect of forgetting on $\mathrm{Tr}$.

From Equation 2 it was predicted that a lapse of $1 \mathrm{~h}$ between successive attacks would lengthen $\mathrm{Tb}$ by $7.7 \%$ for mussels and $5.0 \%$ for dogwhelks, justifying our assumption that the effect of forgetting is insignificant during foraging bouts in which prey are eaten in rapid succession. Resting on this assumption, it was possible to predict the rise in profitability of mussels and dogwhelks to crabs feeding separately on these prey during a foraging bout. Profitability was calculated as the ratio of energy yield to total handling time, where energy yield $=818 \mathrm{~J}(2.10 \mathrm{~cm} \text { mussel })^{-1}$ (Cunningham, 1983) and $305 \mathrm{~J}\left(1.33 \mathrm{~cm}\right.$ dogwhelk) ${ }^{-1}$ (Cunningham, 1983), and total handling time $=\mathrm{Tb}+\mathrm{Tr}+$ eating time for mussels and $\mathrm{Tb}+$ eating time for dogwhelks. Tb and $\mathrm{Tr}$ were predicted using Equation 1 and eating time was assumed to be constant at $295 \mathrm{~s}$ for mussels and $115 \mathrm{~s}$ for dogwhelks (Cunningham, 1983). Eating time may be prolonged when crabs approach satiation, but this was not investigated.

Learning markedly affected the profitability of both species of prey, such that the maximum for mussels was 2.3 times greater than the minimum for dogwhelks and the maximum for dogwhelks was 1.6 times the minimum for mussels (Fig. 6). Mussels could be less profitable than dogwhelks because, even though containing more flesh, extra time was required to remove mussels from a clump and to glean the flesh from a broken shell (Cunningham, 1983). Transposition of ranks in profitability to 5.5 to $7.0 \mathrm{~cm}$ shorecrabs of 1.0 to $2.8 \mathrm{~cm}$ mussels and 0.9 to $1.9 \mathrm{~cm}$ dogwhelks would

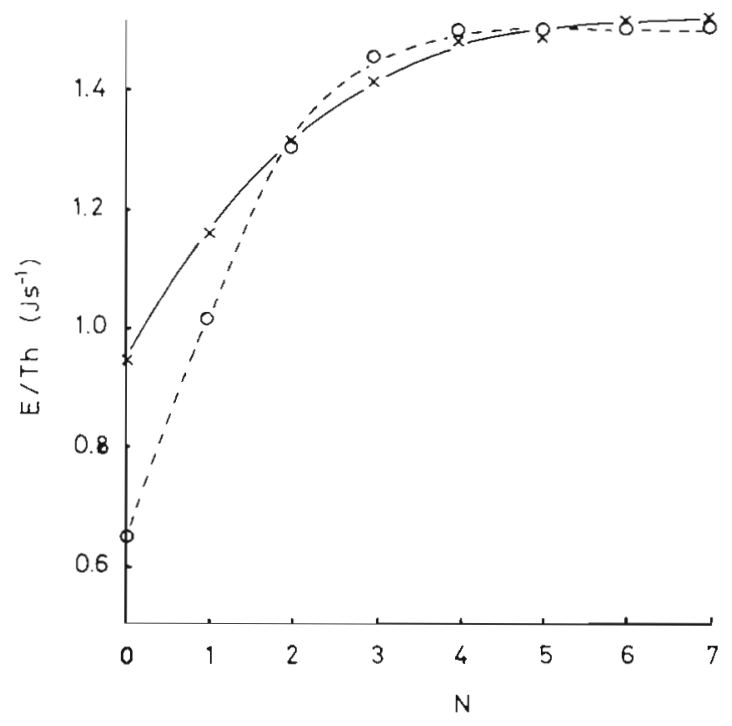

Fig. 6. Carcinus maenas. Profitabilities of consecutive prey items eaten during a foraging bout, predicted from the yield of flesh and the total handling time (see 'Discussion'). Curves fitted by eye. $x$ mussels of 1.0 to $2.8 \mathrm{~cm}$ shell length; $O$ dogwhelks of 0.9 to $1.9 \mathrm{~cm}$ shell height

be possible if one prey species were eaten in rapid succession during a foraging bout. The consumption of both mussels and dogwhelks during a foraging bout reduces learning efficiency (Fig. 1 and 3), but even with a mixed diet, calculations show that it would be possible for the profitabilities of the prey to be transposed if one species were encountered and eaten in rapid succession and the other encountered less frequently.

Since learning minimizes handling time within a sequence of 5 to 6 consecutively eaten items (Fig. 1), a patchy distribution of mussels and dogwhelks theoretically could lead to transpositions in profitability and hence to switching by foraging shorecrabs. Two factors, however, render this unlikely in the field. First, shorecrabs do not remain in one location between foraging bouts, but migrate extensively with the tide (Dare and Edwards, 1981); second, transposition in profitability depends critically on the relative sizes of the shorecrabs, mussels and dogwhelks, with the result that in many natural situations the profitabilities of mussels and dogwhelks will be too different for transposition to be possible (Hughes, 1979; Hughes and Elner, 1979). We have shown, however, that shorecrabs possess a behavioural mechanism that would allow switching to take place under appropriate circumstances.

Acknowledgements. P.N.C. was supported by a N.E.R.C. postgraduate research studentship and R.N.H. by N.E.R.C. grant GR3 3695, for which we are grateful. 


\section{LITERATURE CITED}

Akre, B. G., Johnson, D. M. (1979). Switching and sigmoid functional response curves by damselfly naiads with alternative prey available. J. Anim. Ecol. 48: 703-720

Charnov, E. L. (1976). Optimal foraging: attack strategy of a mantid. Am. Nat. 110: 141-151

Clark, B. C. (1969). The evidence for apostatic selection. Heredity 24: 347-352

Collins, M. D., Ward, S. A., Dixon, A. F. G. (1981) Handling time and the functional response of Aphelinus thomsoni, a predator and parasite of the aphid Drepanosiphum platanoidis. J. Anim. Ecol. 50:479-487

Cunningham, P. N. (1983). Predatory activities of shorecrab populations. Ph. D. thesis, University of Wales

Elner, R. W. (1978). The mechanics of predation by the shore crab, Carcinus maenas (L.), on the edible mussel, Mytilus edulis L. Oecologia (Berl.) 36: 333-344

Elner, R. W., Hughes, R. N. (1978). Energy maximization in the diet of the shore crab, Carcinus maenas. J. Anim. Ecol. $4^{r}$ : $103-116$
Giller, P. S. (1980). The control of handling time and its effects on the foraging strategy of a heteropteran predator, Notonecta. J. Anim. Ecol. 49: 699-712

Hughes, R. N. (1979). Optimal diets under the energy maximization premise: the effects of recognition time and learning. Am. Nat. 113: 209-221

Hughes, R. N., Elner, R. W. (1979). Tactics of a predator, Carcinus maenas, and morphological responses of the prey, Nucella lapillus. J. Anim. Ecol. 48: 65-78

Lawton, J. H., Beddington, J. R., Bonser, R. (1974). Switching in invertebrate predators. In: Usher, M. B, Williamson, M. W. (ed.) Ecological stability. Chapman \& Hall, London, p. 141-158

Murdoch, W. W. (1969). Switching in general predators: experiments on predator specificity and stability of prey populations. Ecol. Monogr. 39: 335-354

Murdoch, W. W., Oaten, A. (1975). Predation and population stability. Adv. Ecol. Res. 9: 1-131

Tinbergen, L. (1960). The natural control of insects in pine woods. I. Factors influencing the intensity of predation in song birds. Archs néerl. Zool. 13: 265-343

This paper was presented by Dr. B. L. Bayne; it was accepted for printing on November 6, 1983 